\title{
Difficulties in Academic Writing: From the Perspective of King Saud University Postgraduate Students
}

\author{
Hind Al Fadda \\ King Saud University, Saudi Arabia \\ E-mail: halfadda@ksu.edu.sa
}

Received: October 5, 2011

Accepted: November 4, 2011

Published: March 1, 2012

doi:10.5539/elt.v5n3p123

URL: http://dx.doi.org/10.5539/elt.v5n3p123

\begin{abstract}
The purpose of this study was to determine what difficulties King Saud University students encounter when learning to write academic English and to differentiate between students' learning needs and objectives. The sample consisted of 50 postgraduate students enrolled in King Saud University during the academic year 2009-2010. Analysis of the data showed that English as a second language (ESL) students face many difficulties and stresses in their academic writing, such as difficulty distinguishing between spoken and written English, making an outline before writing a draft, identifying the skills needed for successful writing, and avoiding plague words and phrases.
\end{abstract}

Keywords: Academic writing, Difficulty, ESL, Postgraduate

\section{Introduction}

Academic writing in English at advanced levels is a challenge even for most native English speakers. However, it is particularly difficult for English as a second language (ESL) graduate students, who come from non-Anglicized linguistic and cultural backgrounds, particularly Asian graduate students.

\section{Statement of the Problem}

For many adult ESL learners, learning to write in academic English is a difficult and challenging task. Few adult ESL learners have had much experience writing in academic English. Not only must these ESL students gain proficiency in grammar, mechanics, vocabulary, and other surface-level aspects of English composition, they must master American and/or British rhetorical styles and writing genres. The ESL learner's ability to write in academic English may be influenced by factors such as writing style, motivation, anxiety over expression, writer's block, and other emotional factors. ESL students' native language literacy backgrounds and experiences are also very important in the development of their academic writing.

\section{Purpose of the Study}

The goal of this study is to determine what difficulties King Saudi University (KSU) students encounter when learning to write academic English and differentiate between what students need in order to learn and what their objectives are in learning.

\section{Significance of the Study}

In the Kingdom of Saudi Arabia (KSA), the English language curriculum is one of the Ministry of Education's major concerns. Consequently, it is important to consider academic writing at the university level and identify the difficulties students face in this area.

\section{Research Questions}

This research is guided by three major questions:

1. From the ESL students' perspective, what stresses, if any, are experienced in learning to write in academic English?

2. From the students' perspective, what teaching approaches to academic writing either facilitate or impede success?

3. From the students' perspective, what role, if any, does interaction with native English speakers have in improving academic writing?

\section{Literature Review}

Recent studies have researched the difficulties of academic writing. This study sheds light on previous studies and 
reviews relevant literature according to the following categories:

6.1 Definition of academic writing

6.2 Basics of academic writing

6.3 Characteristics of good academic writing

6.4 Challenges of teaching academic writing to postgraduate students

\subsection{Definition of Academic Writing}

Academic writing is a mental and cognitive activity, since it is a product of the mind. The image of an individual working alone in a quiet environment has furthered the view of writing as a mental and cognitive activity. However, as has been pointed out, "writing can be understood only from the perspective of a society rather than a single individual" (Burke, 2010, p. 40-41).

\subsection{Basics of Academic Writing}

Academic writing is expected to address an intellectual community in which the students engage in active learning. Some basics or rules must be established. Using information to one's advantage is a key part of learning. Success at the postgraduate level depends on the students' ability to access, evaluate, and synthesize the words, ideas, and opinions of others in order to develop their own academic voice. When presenting what they have learned, it is therefore vitally important that students are able to show clearly what they have drawn from others and what is their own (Bristol Business School, 2006, p. 3).

A student must be honest about how much ownership he/she can claim over the ideas formed, the answers found, and the opinions expressed (Bristol Business School, 2006, p. 3). The student must follow certain rules to ensure good academic writing, including punctuation guidelines.

\subsubsection{Punctuation}

The essential punctuation marks (excluding usage in reference systems) are the period, comma, semicolon, and colon. These include the following:

- The period primarily marks the end of a sentence. A period is also used after an abbreviation where the final letter of the word is not the final word of the abbreviation, e.g., in enc. for enclosure, although Mr. for Mister is an exception (Murphy, 2010, p. 9).

- The comma is primarily used to separate parts of a sentence so that the meaning remains clearer for the reader.

(I) A comma separates words in a list, e.g., He brought coal, kindling, matches, and turf.

(II) A comma separates subordinate clauses within a complex sentence where two separate sentences are not required (Murphy, 2010, p. 9).

- The semicolon has two common uses. First, it may be used to separate items in a list after a colon. Second, it may be used to indicate a certain relationship between two parts of a sentence (Murphy, 2010, p. 9).

- The colon may be used to indicate the start of a list, as is similar to the above example for the semicolon. It may also be used before a quotation begins (Murphy, 2010, p. 9).

- The dash it is used to enclose a group of words in a sentence where a list of items is separated by commas. (Murphy, 2010, p. 9).

- An omission (where words are deliberately left out) is noted by the use of three periods (an ellipsis) followed by a space. If the omission occurs at the end of a sentence, the ellipsis follows the period.

- Parentheses/brackets are used to enclose information of minor importance in a sentence. Brackets are useful if a writer is restricted to the use of footnotes (Murphy, 2010, p. 10).

- The hyphen is used within compound words such as co-opt, half-day, two-thirds, three-week holidays, inner-city streets, student-centered, problem-based (Murphy, 2010, p. 10).

- Italics are used for titles of books, plays, films, etc., and some names, such as those of planes or ships, etc. (Murphy, 2010, p. 10).

- Capital letters are used for names and titles, the first word in a sentence, and acronyms, e.g., NQAI (Murphy, 2010, p. 10).

- Numbers fewer than one hundred are generally spelled out. When a number is the first word in a sentence, it is spelled out regardless of its size. Hyphens are used when numbers are spelled out, e.g., twenty-nine. Street numbers 
are given in figures, e.g., 12 Upper Mount Street. A number used in a date is not spelled out, e.g., January 14, nor is time, e.g., 12:30 pm. Decades, such as the 1990s, have an "s" added to them with no preceding apostrophe (Murphy, 2010, p. 10).

- An apostrophe has no primary purpose. These are largely used to show ownership and indicate that a letter or letters have been left out. (Murphy, 2010, p. 10).

- Quotations present information and ideas that the student has gathered from other sources. Academic honesty requires that the student provide documentation to indicate the sources of the information and ideas (Troyka and Hesse, 2006, p. 51).

- $\quad$ Foreign words and phrases with popular abbreviations (particularly Latin and French words) are frequently used when writing in other languages. The convention in academic writing is to use italics or abbreviations for foreign words or phrases and abbreviations (Murphy, 2010, p. 11).

- $\quad$ Footnotes and endnotes are important, along with references and bibliographies, because they inform readers of who said what, where, and when. When the student provides this information, readers consider their ideas to be buttressed by the ideas of experts and are more likely to engage in those ideas (Fulwiler, 2002, p. 59).

\subsection{Characteristics of Good Academic Writing}

Yugianingrum identified four characteristics of good academic writing:

- Writing should play a significant role in the related community.

- The topic should be interesting for the writer, who believes that there is more to discover about it.

- The writer must care about the aesthetic quality of the text he/she writes.

- The community should help writers in accessing relevant resources and finding support and guidance. (Yugianingrum, 2010, pp. 40-41)

\subsection{Challenges of Teaching Academic Writing to Postgraduate Students}

First, writing usually suffers from a lack of interaction, which stimulates oral production in conversation (Shafie, Maesin, Osman, Nayan, and Mansor, 2010, p. 61). Often, in higher education, writing tasks require students to draw on outside sources and adopt the styles and genres of academic discourse (Tardy, 2010, p. 12).

Confidence in writing ability is a must. Cafarella and Barnett found that students' lack of confidence in their writing ability made it harder to make revision decisions and explain these decisions to the feedback providers. This was especially the case when there was conflicting feedback from different faculty (Can, 2009, 25)

One of the difficulties of writing in a second or additional language is that it is generally believed to require some mastery of writing in the first language. There seems to be a perception that once learners can write sentences and paragraphs in their first language, they will automatically transfer such skills to other languages. However, it has to be noted that this may be possible only if a certain degree of proficiency in the first language is attained (Kereni, 2004, 12).

Second, instructors continuously complain about the lack of knowledge and certain skills necessary for academic writing among non-native speakers of English. Some of these skills involve outlining, paraphrasing, and summarizing (Al-Shabanah and Maher, 2005, p. 2).

Third, academic writing often requires students to write from an expert position, even when they do not consider themselves experts on their topics (Tardy, 2010, p. 13).

Essays and related written work provide opportunities for students to demonstrate some of the most demanding learning outcomes; however, students are often more confused about what constitutes a good essay than they are about the criteria for other types of assignments (Elander et al., 2006, 72).

The lecturers struggled in their role of assisting international students with academic writing. While they all acknowledged that it was important to offer students assistance in the form of criteria sheets, they also indicted that they found it challenging to give advice to students on academic writing, and regarded themselves as being unclear about what that advice should be (Arkoudis \& Tran, 2010, 175).

Additionally, poor language proficiency remains an issue. Novice writers have particularly poor language proficiency, and, due to this factor, cannot conduct effective discussions in the target language. Warschauer argues that oral language proficiency is very important for any learner of language, because it is the most widely used skill (Shafie et al., 2010, p. 63).

Teachers, then, have an important role in helping students develop their awareness of the effects of self-mentioning, 
and enabling them to recognize both the choices available to them and the impact of those choices. With this understanding, our learners will be better able to gain control over their writing and meet the considerable challenges of academic writing in a second language (Hyland, 2002, 357).

\section{Methodology}

\subsection{Research Approach and Design}

This research adopted the analytic descriptive approach to facilitate the gathering of information and data to assist in achieving study goals.

\subsection{Population}

The population comprised KSU postgraduate university students.

\subsection{Sampling Process and Subjects}

The study was conducted with a sample of fifty KSU postgraduate students during the 2009-2010 academic year. The description of the study sample is presented in Tables $1-3$.

\subsection{Material}

A university course for KSA postgraduate students helped identify academic writing difficulties.

\subsection{Instrumentation}

The current study depended on a questionnaire as the main instrument for obtaining the required information.

\subsection{Analysis of Data}

Once the data had been collected, the appropriate statistical tests were performed to analyze the data, test the hypotheses, and answer the research questions. All data that were captured by the questionnaire were coded. All data analysis for the project was conducted using the statistical package SPSS 15. Descriptive statistics included means and standard deviations used to assess the basic characteristics of the study population. In addition, the Pearson correlation coefficient and ANOVA test were used to examine significant differences in the subjects' responses across different elements, which were then used to identify correlations between the research variables.

\section{Presentation and Interpretation of Data}

\subsection{Testing Question}

The first research question, "From the ESL students' perspective, what stresses, if any, are experienced in learning to write in academic English," tested the following hypothesis:

- Distinguishing stylistic differences between spoken and written English in English texts is one of the major difficulties students in KSA Universities face.

In order to investigate this first hypothesis, the mean scores and standard deviations were calculated. The results are shown in Table 4.

The results were consistent with those of many studies, such as Parsons (2010) and Yong (2010), which have discussed the difficulties of academic writing.

The second research question, "From the students' perspective, which teaching approaches to academic writing either facilitate or impede success," tested the following hypothesis:

- Certain teaching approaches can facilitate or impede success in academic writing. From the students' perspective, many approaches were seen to facilitate success.

One example was computer-assisted writing instruction, which addressed many levels (the sentence, paragraph, and essay levels). All these levels helped students practice academic writing in different styles. Conversely, there were also many approaches, such as different requirements or different styles, which impeded students' in academic writing.

The third research question, "From the students' perspective, what role, if any, does interaction with native English speakers have in improving academic writing," tested the following hypothesis:

- Native English speakers play an important role in the improvement of academic writing among ESL students.

Students considered interaction with native English speakers to be very important in improving their academic writing, since native English speakers could provide ESL students with guidance on how to write a thesis; how to write a coherent paragraph; how to differentiate between compounds and modifiers; how to place modifiers correctly; how to determine which skills are important for professional academic writing; and how to avoid 
grammatical mistakes in writing. Yugianingrum (2010) confirmed this result when he emphasized the importance of finding solutions to academic writing problems.

\subsection{Research Question One}

From the ESL students' perspective, what stresses, if any, are experienced when learning to write in academic English?

As shown in the results in Table 4, the mean scores indicate that students face many difficulties in academic writing, such as:

1- Knowing the plague words and phrases they should avoid.

2- Reviewing the grammar in their writing.

3- Experiencing difficulty in using pronouns and maintaining pronoun-antecedent agreement.

4- Making mistakes with subject-verb agreement.

5- Making sentence fragments in their writing.

6- Experiencing difficulty when combining sentences in their writing.

The findings above explain why most Saudi students, who tend to speak fluently, still have poor writing skills. If we were to examine the Arabic language, we would find that it tends to use metaphoric, lengthy sentences, while academic writing in English is quite the opposite.

\subsection{Research Question Two}

From the students' perspective, what teaching approaches to academic writing either facilitate or impede success?

According to the questionnaire results, we can note that there are many approaches that facilitate students' success in academic writing. The following are a few examples:

1 -Writing an outline before writing a draft.

2-Including each of the three steps (planning, writing, and revision) in their writing process.

3- Reviewing what they have written before submission.

On the other hand, there are many additional approaches, such as differences in requirements or styles, that impede students' success in academic writing.

\subsection{Research Question Three}

From the students' perspective, what role, if any, does interaction with native English speakers have in improving academic writing?

Students thought interaction with native English speakers improved their academic writing, as native speakers could provide them with guidance on how to write a thesis; how to write a coherent paragraph; how to differentiate between compounds and modifiers; how to effectively place modifiers; how to determine which skills are important for professional academic writing; and how to avoid grammatical mistakes in their writing.

\section{Implications and Suggestions}

\subsection{Conclusions}

In view of the data presented, the following conclusions were reached regarding the difficulties of academic writing:

- ESL students face many difficulties and stresses in their academic writing, including those caused by distinguishing between spoken and written styles in English texts. Regarding this point, I must mention that Arabic is quite different from English in both its spoken and written forms. Factors attributing to these differences include: a) differences in alphabets and b) differences in writing styles, in that Arabic tends to have more metaphoric phrases and lengthier sentences than English does.

- There are many approaches for teaching academic writing; some of them can facilitate success, such as computer-assisted writing instruction, and others can impede success, such as the use of different writing styles.

- Native English speakers can play an important role in the improvement of ESL students' academic writing, as native speakers can help these students identify the skills important for such writing.

\subsection{Suggestions for Further Research}

The following recommendations are made for future studies: 
- $\quad$ The present study could be replicated on a wider scale that includes diverse populations and various levels of education to examine more thoroughly the difficulties of academic writing.

- Further field-based research should be conducted to address other important skills, such as reading, listening, and speaking.

- Since the subjects of this study were male and female students, future studies could be conducted with only male or only female students to determine the effect of gender on academic writing difficulties.

\section{References}

Al-Khasawneh, F., \& Maher, S. (2010). Writing for Academic Purposes: Problems Faced by Arab Postgraduate Students of the College of Business, UUM. ESP World. 9, 1-23

Al-Shabanah, A. I. (2005). Summarization strategies adopted by the senior level female students of the Department of English at King Saud University. Master's thesis.

Anderson, I. (2009). Avoiding Plagiarism in Academic Writing. Nursing Standard. 23, 35-37

Arkoudis, S., \& Tran, L. (2010). Writing Blah, Blah, Blah: Lecturers' Approaches and Challenges in Supporting International Students. International Journal of Teaching and Learning in Higher Education, 22, 169-178

BBC English Teachers' Supplement. (1995). The challenges of teaching academic writing. [Online] Available: http://www.uefap.com/articles/furneaux.pdf

Bristol Business School. (2006). Doing it right - Good practice in academic writing for postgraduate students. [Online]Available:

http://www.brad.ac.uk/learnerdevelopment/media/LearnerDevelopmentUnit/Documents/AcademicSkillsResources/ WritingPGskills/Teach_Yourself_Good_Writing_Practice_for_PGs.pdf

Burke, S. B. (2010). The construction of writer identity in the academic writing of Korean ESL students: a qualitative study of six Korean students in the U.S. Doctoral dissertation.

Can, G. (2009). A model for doctoral students' perceptions and attitudes toward written feedback for academic writing. Doctoral dissertation.

Elander, J., Harrington, K., Norton, L., Robinson, H., \& Reddy, P. (2006). Complex Skills and Academic Writing: A Review of Evidence About the Types of Learning Required to Meet Core Assessment Criteria. Assessment \& Evaluation in Higher Education, 31, 71-90. http://dx.doi.org/10.1080/02602930500262379

Fulwiler, Toby. (2002). A personal approach to academic writing. College writing: Third Edition. Boynton/Cook Publishers, Inc. Heinemann.

Hyland, K. (2002). Options of Identity in Academic Writing. ELT Journal, 56, 351-358. http://dx.doi.org/10.1093/elt/56.4.351

Irvin, Le. (2010). What is "academic" writing? [Online] Available: http://wac.colostate.edu/books/writingspaces1/irvin--what-is-academic-writing.pdf

Kereni, I. (2004). Developing academic writing at the National University of Rawanda: a case study of first year economics and management. Master's thesis.

Murphy, Anne. (2010). Academic writing and publishing matters for the scholar-researcher. D.I.T Dublin Institute of technology.

Shafie, L. A., Maesin, A., Osman, N., Nayan, S., \& Mansor, M. (2010). Understanding Collaborative Academic Writing Among Beginner University Writers in Malaysia. Studies in Literature and Language, 1, 58-69

Tardy, C. M. (2010). Writing for the World: Wikipedia as an Introduction to Academic Writing. English Teaching Forum, 1, 12-27

Tauguchi, H. L. (2006). Deconstructing and reconceptualizing academic writing towards a more 'just' teacher education. Working paper.

Troyka, L. Q., \& D. Hesse, Simon \& Schuster Handbook for Writers. (2006). Guidelines for Academic Writing. Fourth Canadian Edition. Toronto: Pearson Prentice Hall

The English Language Centre, Deanery of Academic Services. (2011). Inside the Saudi Preparatory Year English Programme: the future and beyond. Proceedings of the TULC11, Taibah University, Medina, Saudi Arabia.

Woodrow, L. (2006). Academic Success of International Postgraduate Education Students and the Role of English Proficiency. University of Sydney Papers in TESOL, 1, 51-70 
Yugianingrum. (2010). Producing an English Academic Paper: Process, Problems, and Solutions. US-China Foreign Language, 8, 39-49

Table 1. Distribution of the study sample according to Gender

GENDER

\begin{tabular}{|llrrrr|}
\hline & & & & \multicolumn{2}{c|}{ Cumulative } \\
Vercent
\end{tabular}

Table 2. Distribution of the study sample according to Age

AGE

\begin{tabular}{|llrrrr|}
\hline & & & & & Cumulative \\
Valid & $20<30$ & Frequency & Percent & Valid Percent & Percent \\
& $30<35$ & 35 & 70.0 & 70.0 & 70.0 \\
& 35 & 6.0 & 6.0 & 76.0 \\
& 3540 & 12 & 24.0 & 24.0 & 100.0 \\
Total & 50 & 100.0 & 100.0 & \\
\hline
\end{tabular}

Table 3. Distribution of the study sample according to English Proficiency

ENGLISH PROFICIENCY

\begin{tabular}{|llcrrr|}
\hline & & & & \multicolumn{2}{c|}{ Cumulative } \\
\hline Valid & Beginner & 4 & 8.0 & 8.0 & Percent \\
& Medium & 12 & 24.0 & 24.0 & 8.0 \\
& Advanced & 34 & 68.0 & 68.0 & 100.0 \\
& Total & 50 & 100.0 & 100.0 & \\
\hline
\end{tabular}

Table 4. Mean and standard deviation percentages for students' responses on the questionnaire

\begin{tabular}{|c|c|c|c|c|c|c|c|c|c|}
\hline $\begin{array}{l}\text { Rank } \\
\text { Standard } \\
\text { deviation }\end{array}$ & & $\begin{array}{l}\text { Mean } \\
\text { scores }\end{array}$ & $\begin{array}{l}\text { No } \\
\text { Percentage }\end{array}$ & Frequency & $\begin{array}{l}\text { No idea } \\
\text { Percentage }\end{array}$ & Frequency & $\begin{array}{l}\text { Yes } \\
\text { Percentage }\end{array}$ & Frequency & $\begin{array}{l}\text { Academic writing } \\
\text { difficulties }\end{array}$ \\
\hline 12 & .7626 & 1.50 & 66.0 & 33 & 18.0 & 9 & 16.0 & 8 & $\begin{array}{l}\text { Will the grammatical } \\
\text { features be one of the } \\
\text { problems you face in your } \\
\text { English writing? }\end{array}$ \\
\hline 2 & .7559 & 2.60 & 16.0 & 8 & 8.0 & 4 & 76.0 & 38 & $\begin{array}{l}\text { Will you spend time } \\
\text { reviewing what you write? }\end{array}$ \\
\hline 7 & .9267 & 2.28 & 32.0 & 16 & 8.0 & 4 & 60.0 & 30 & $\begin{array}{l}\text { Does most of your } \\
\text { reviewing focus on the } \\
\text { sentence and paragraph } \\
\text { level? }\end{array}$ \\
\hline 5 & .9424 & 2.36 & 32.0 & 16 & 0 & 0 & 68.0 & 34 & $\begin{array}{l}\text { Do you always focus your } \\
\text { reviewing on the grammar }\end{array}$ \\
\hline
\end{tabular}




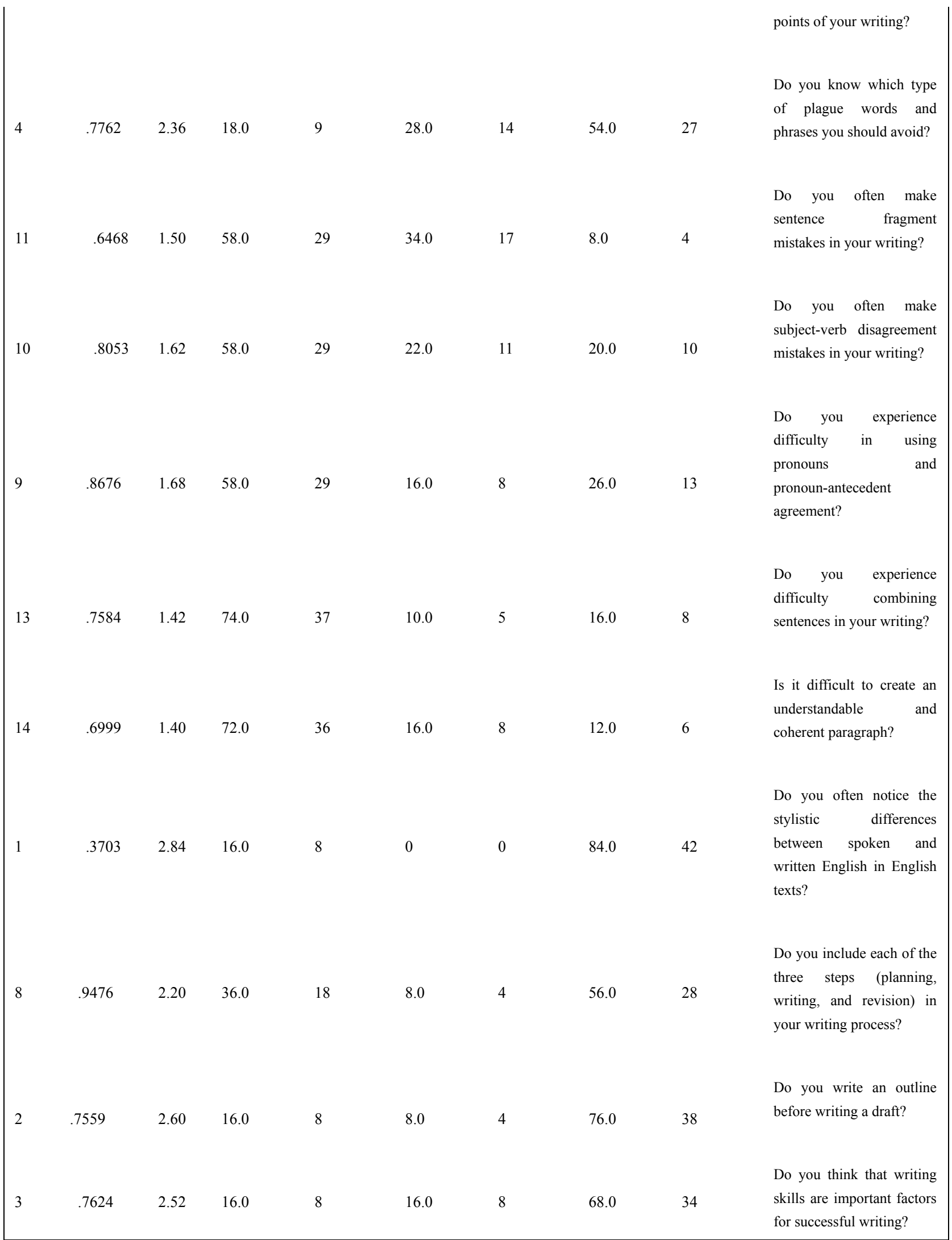

